\title{
Overlap of burnout-depression symptoms among Chinese neurology graduate students in a national cross-sectional study
}

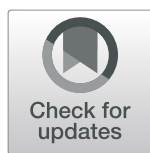

Wei Zhou ${ }^{1,2 \dagger}$, Juncai Pu ${ }^{2,3 \dagger}$, Xiaogang Zhong ${ }^{1,4 \dagger}$, Wensong Yang ${ }^{2,3}$, Teng Teng ${ }^{2,3}$, Li Fan ${ }^{2,3}$, Haiyang Wang ${ }^{2,5}$, Lu Tian ${ }^{1,2}$, Yiyun Liü ${ }^{2}$ and Peng Xie ${\text { I, } 2,3,6^{*}}^{1}$

\begin{abstract}
Background: The overlap of burnout and depression is a phenomenon that can effectively reflect the psychological state of a group. However, whether burnout is a type of depression is still debated in current research. The high incidence of burnout and depressive symptoms among medical students indicates that it is urgent to provide appropriate health services for them. However, the proportion of burnout and depression in the overlapping symptoms experienced by medical students, and the characteristics of the relative influencing factors, remain unclear. Therefore, we addressed these issues for neurology graduate students in China.

Methods: Using data from a cross-sectional survey of Chinese neurology graduate students, a diagnostic model was established according to their burnout and/or depression symptoms. Burnout was assessed by using the Maslach Burnout Inventory. Depression symptoms were assessed with a two-item depression screening tool for primary care evaluation of mental disorders. Univariate analyses with chi-squared tests were conducted to assess associations between variables. Multinomial logistic regression models were used to analyze the effects of multiple factors on dependent variables. The factors included demographic information and three medical-study related problems.

Results: In total, $32.2 \%$ of surveyed students evidenced overlapping burnout and depression symptoms. Students with depressive symptoms tended to be included in the burnout students' category. In the regression model, being unmarried, having children, and career choice regret were related to students who had only burnout, while the students with overlapping symptoms were affected by more factors such as family income, the consideration of dropping out once.

(Continued on next page)
\end{abstract}

\footnotetext{
* Correspondence: xiepeng@cqmu.edu.cn

${ }^{+}$Wei Zhou, Juncai Pu and Xiaogang Zhong contributed equally to this work.

'School of Public Health and Management, Chongqing Medical University,

Chongqing 400016, China

${ }^{2} \mathrm{NHC}$ Key Laboratory of Diagnosis and Treatment on Brain Functional

Diseases, The First Affiliated Hospital of Chongqing Medical University,

Yuzhong District, Chongqing, China

Full list of author information is available at the end of the article
}

C C The Author(s). 2021 Open Access This article is licensed under a Creative Commons Attribution 4.0 International License, which permits use, sharing, adaptation, distribution and reproduction in any medium or format, as long as you give appropriate credit to the original author(s) and the source, provide a link to the Creative Commons licence, and indicate if changes were made. The images or other third party material in this article are included in the article's Creative Commons licence, unless indicated otherwise in a credit line to the material. If material is not included in the article's Creative Commons licence and your intended use is not permitted by statutory regulation or exceeds the permitted use, you will need to obtain permission directly from the copyright holder. To view a copy of this licence, visit http://creativecommons.org/licenses/by/4.0/ The Creative Commons Public Domain Dedication waiver (http://creativecommons.org/publicdomain/zero/1.0/) applies to the data made available in this article, unless otherwise stated in a credit line to the data. 
(Continued from previous page)

Conclusions: The symptoms and related factors of burnout and depression among Chinese neurology postgraduates have obvious overlap and show a significant trend. The occurrence of depressive symptoms among medical students is closely related to whether they are burned out. Students with only burnout were common, but students with only depressive symptoms were uncommon. Finally, burnout may be a pre-depression state.

Keywords: Overlap, Neurology, Postgraduates, Burnout, Depressive symptoms

\section{Background}

Burnout includes three dimensions of exhaustion, cynicism and lack professional efficacy $[1,2]$. It is a more contextualized mental health problem and is thought to be related to depressive symptoms in the work environment $[3,4]$. Depression symptoms include low mood, anhedonia, fatigue overlap with burnout and there is a strong correlation between them [5]. Burnout and depressive symptoms were determined to be influenced by common factors, such as work stress $[6,7]$. The study of their overlap is a highly contentious area.

Reports around the world have increasingly pointed out that medical students' experience high levels of burnout and depressive symptoms [8-11]. A study that covered 43 countries in 2016 showed prevalence of depressive symptoms among medical students was $27.2 \%$ [12], and another study reported in 2019 showed that the incidence of burnout among medical students was $44 \%$ [13]. Burnout or depressive symptoms of medical students were affected by career choice motivation, poor economic status, relatives and other dangerous factors $[14,15]$. At the same time, it has been shown to impact students extremely negatively, producing self-reported unprofessional conduct, less altruistic professional values, declining interest in a medical career, increasing suicidal ideation, among other outcomes [16-18]. Overall, the cited studies highlight that burnout and depressive symptoms are important issues affecting the mental health of medical students. Our previous studies have discussed the characteristics of burnout and depressive symptoms among Chinese neurology graduate students, respectively $[19,20]$. While these findings have improved our understanding of medical students' mental health issues, more recent studies have begun to focus on the overlap between burnout and depressive symptoms, and have offered judgments that better reflect the social reality $[7,21]$. To this end, some scholars have investigated this overlap relationship by using input from physicians, school administrators, and health professionals [22-24]. They have shown that, in their study populations, burnout and depressive symptoms were indivisible and, furthermore, were probably the same symptoms [22-24].

Another study showed that individuals with severe burnout were significantly more likely to use antidepressants [25]. This suggests that burnout is worthy of attention in clinical practice. Thus, re-examining burnout and depressive symptoms can provide a basis for further identification and treatment. Importantly, the nature of medical education has made medical students to pay more attention to the stigma of mental illness. And the effects of burnout, depression, and suicidal ideation on medical students is more serious than that on the general population [26].

To our knowledge, there are few studies on the overlap between burnout and depressive symptoms among medical students. Moreover, the degree and the risk factors of overlap are not clear. The aim of this study was to investigated the features of overlapping symptoms of depression and burnout in a large sample of Chinese neurology graduate students, and further established a corresponding diagnostic model.

\section{Methods \\ Participants}

Using a cross-sectional study design, a national selfadministered questionnaire survey was conducted among 1814 neurology postgraduates in China from September 2014 to March 2015 [19, 20, 27]. Participants were recruited from 249 hospitals in 27 provinces across the country $[19,20]$. Survey responses were voluntary and anonymous. Consent was assumed for any participant who returned a completed survey. All methods were performed in accordance with the relevant guidelines and regulations. The study was reviewed and granted approval by the Ethics Committee of Chongqing Medical University.

\section{Outcome measures}

Validated surveys were used to measure burnout and depressive symptoms. Demographic data and three questions related to studying medicine were collected to measure factors associated with burnout and depressive symptoms. Demographic characteristics comprised gender, academic year, family monthly income, type of degree, postgraduate entrance examination score, hours worked or studied per week, hours slept per day, marital status, whether have children, and part-time work experience [19]. The three questions related to studying medicine were: "If you could go back, would you choose to become a doctor again?"; "What do you think of the 
current medical environment?"; and, "Have you ever considered dropping out of school?"

The Maslach Burnout Inventory was used to evaluate burnout; its three dimensions are: emotional exhaustion (9 items), depersonalization (5 items), and personal accomplishment (8 items) [1,28]. Participants rated their answers on a 7 -point frequency scale $(0=$ Never, $1=\mathrm{a}$ few times a year or less, $2=$ once a month or less, $3=$ several times a month, $4=$ once a week, $5=$ a few times a week, $6=$ every day). Respondents were considered to have burnout if they scored higher on the emotional exhaustion $(\geq 27)$ and/or depersonalization $(\geq 10)$ subscales [16].

The two-item primary care evaluation of mental disorders (PRIME-MD) was used to assess depressive symptoms [29]. Participants' positive response to either of the following items was considered evidence of depressive symptoms: "In the last month, did you often feel in low spirits, depressed or hopeless?" and, "In the last month, were you often troubled by the feeling that you were not interested or had no fun in doing things?" PRIME-MD has been widely adopted for the assessment of depression symptoms in medical students [30,31].

\section{Statistical analysis}

Data analyses were conducted by using IBM SPSS version 21(IBM Corp., Armonk, N.Y., USA). Data were divided into four categories according to participants' scores: 1) no burnout or depressive symptoms, 2) burnout but no depressive symptoms, 3) depressive symptoms but no burnout, 4) both burnout and depressive symptoms. Univariate analyses with chi-squared tests were conducted to assess associations between variables. All variables with $p \leq 0.1$ in the univariate analysis were included in the multinomial logistic regression model, and the significance level (alpha) of variable selection was set at 0.05 for both entry and exit in the logistic regression models. Multicollinearity analysis was used to test collinearity among variables when the tolerance was $\leq 0.1$ or the variance inflation factor was $\geq 10$ [19]. The significance level was set at 0.05 .

\section{Results}

\section{Descriptive analysis}

The demographics, the answers to three questions about studying medicine, and mental health characteristics of the sample are summarized in Table 1. Overall, $51.4 \%$ of students evidenced burnout alone, $1.5 \%$ suffered from depressive symptoms alone, and $32.2 \%$ had both burnout and depression symptoms. Both clinical degree and women made up more than $50 \%$ of the students in four categories. In addition, less than $10 \%$ of students in each category felt the medical environment was good. In the univariate analysis of multiple groups, academic year, family monthly income, postgraduate entrance examination score, hours slept per day, marital status, whether have children, view on current medical environment, career choice regret, and considered dropping out once were statistically different between groups $(p<0.05)$.

\section{Multinomial analysis}

Multinomial logistic regression results comparing students without burnout or depressive symptoms with those who suffered only from burnout showed that being married (OR $=0.44,95 \%$ CI $0.29-0.69)$ was the protective factor for those in the latter group. However, having children $(\mathrm{OR}=1.79,95 \%$ CI $1.17-1.74)$ and career choice regret $(\mathrm{OR}=2.62,95 \% \mathrm{CI} 1.56-3.28)$ had a higher risk for students with only burnout. Moreover, students with only burnout who reported career choice regret neutral $(\mathrm{OR}=2.98,95 \% \mathrm{CI} 1.84-4.80)$ were also at higher risk. Similar factors and results also appeared in the comparison between unaffected students and students with overlapping symptoms of burnout and depression. Furthermore, low family income $(\mathrm{OR}=2.33$, 95\% CI 1.05-5.18) and thoughts of dropping out of school $(\mathrm{OR}=2.62,95 \% \mathrm{CI} 1.55-4.43)$ imposed a higher risk tendency only among students with overlapping symptoms of burnout and depression. The academic year factor was different in the other categories compared with unaffected students; almost all other school years were deemed more serious burnout and/or depression symptoms than the first year master's degree, but not all grades showed significant differences (see Table 2).

\section{Discussion}

This nationwide study was one of the first to study the overlap and differences between burnout and depressive symptoms among Chinese medical students. We found the proportion of overlapping burnout and depression symptoms among the neurology graduate students accounting for nearly a third of the total number of participants, and for the characteristics of influencing factors in the overlap cases.

Studies on burnout and depressive have shown that their relationship is controversial and have provided convincing arguments for all sides of the issue [32-35]. Some scholars believe that burnout and depression are not isomorphic [32]. One view is that, although burnout and depression are closely related, they can be distinguished from each other [33]. Additionally, burnout is limited to work-related situations, while depression is more general [33]. On the other hand, some researchers suggest that burnout is a state of depression rather than an independent entity [34]. Furthermore, some studies suggest that evidence for the validity of the difference between burnout and depression is weak, and that 
Table 1 Characteristics associated with medical students' burnout and (or) depressive symptoms

\begin{tabular}{|c|c|c|c|c|c|}
\hline \multirow[t]{2}{*}{ Characteristics } & \multicolumn{4}{|c|}{ Burnout and Depressive Symptoms } & \multirow{2}{*}{$\begin{array}{l}P \\
\text { Value }\end{array}$} \\
\hline & $\begin{array}{l}B(-) \text { and } D(-)[271, \\
14.9 \%]\end{array}$ & $\begin{array}{l}\text { B (+) and D (-) [932, } \\
51.4 \%]\end{array}$ & $\begin{array}{l}\mathrm{B}(-) \text { and } \mathrm{D}(+)[27, \\
1.5 \%]\end{array}$ & $\begin{array}{l}B(+) \text { and } D(+)[584, \\
32.2 \%]\end{array}$ & \\
\hline Gender, Female & $172_{a}(63.5)$ & $640_{a}(68.8)$ & $14_{a}(51.9)$ & $392_{a}(67.2)$ & 0.13 \\
\hline \multicolumn{5}{|l|}{ Academic year } & $<0.01$ \\
\hline First-year, master's degree & $73_{a}(27.7)$ & $216_{a}(23.6)$ & $1_{a, b}(4.3)$ & $101_{b}(17.7)$ & \\
\hline $\begin{array}{l}\text { Second-year, master's } \\
\text { degree }\end{array}$ & $69_{a}(26.1)$ & $269_{a}(29.4)$ & $8 a, b(34.8)$ & $208_{b}(36.4)$ & \\
\hline Third-year, master's degree & $101_{a}(38.3)$ & $311_{a}(34.0)$ & 8 a $(34.8)$ & $189 \mathrm{a}(33.1)$ & \\
\hline First-year, doctor's degree & $7 \mathrm{a}(2.7)$ & $43_{a}(4.7)$ & $3_{a}(13.0)$ & $26_{a}(4.6)$ & \\
\hline $\begin{array}{l}\text { Second-year, doctor's } \\
\text { degree }\end{array}$ & $8 \mathrm{a}(3.0)$ & $37 a(4.0)$ & $3_{a}(13.0)$ & $26_{a}(4.6)$ & \\
\hline Third-year, doctor's degree & $\sigma_{a}(2.3)$ & $40_{a}(4.4)$ & $0_{a}(0.0)$ & $22_{\mathrm{a}}(3.9)$ & \\
\hline \multicolumn{5}{|c|}{ Degree type } & 0.09 \\
\hline Clinical practice & $194_{a}(72.7)$ & $619_{a}(67.9)$ & $15 a(57.7)$ & $415_{a}(72.7)$ & \\
\hline Academic practice & $73_{a}(27.3)$ & $292_{a}(32.1)$ & $11_{a}(42.3)$ & $156_{a}(27.3)$ & \\
\hline \multicolumn{5}{|c|}{ Family income (yuan per month) } & 0.02 \\
\hline$<5000$ & $145_{a, b}(53.7)$ & $434_{b}(46.8)$ & $9 \mathrm{a}, \mathrm{b}(33.3)$ & $313_{a}(54.1)$ & \\
\hline $5000-10,000$ & $84_{a}(31.1)$ & $315_{a}(33.9)$ & $11_{a}(40.7)$ & $193_{a}(33.3)$ & \\
\hline $10,000-15,000$ & $22_{a}(8.1)$ & $103_{a}(11.1)$ & $5_{a}(18.5)$ & $46_{a}(7.9)$ & \\
\hline$>15,000$ & $19_{a, b}(7.0)$ & $76_{b}(8.2)$ & $2_{a, b}(7.4)$ & $27 a(4.7)$ & \\
\hline \multicolumn{5}{|c|}{ Scores of postgraduate entrance examination } & $<0.01$ \\
\hline$<300$ & $54_{a}(23.2)$ & $93_{b}(11.5)$ & $1_{a, b}(4.3)$ & $73_{a, b}(15.6)$ & \\
\hline $300-330$ & $84_{a}(36.1)$ & $380_{b}(47.0)$ & $9_{a, b}(39.1)$ & $225_{b}(48.0)$ & \\
\hline $330-360$ & $65_{a}(27.9)$ & $229_{a}(28.3)$ & $10_{a}(43.5)$ & $118_{a}(25.2)$ & \\
\hline$>360$ & $30_{a}(12.9)$ & $106_{a}(13.1)$ & $3_{a}(13.0)$ & $53_{a}(11.3)$ & \\
\hline \multicolumn{5}{|c|}{ Hours worked or studied per week (h) } & 0.05 \\
\hline$<35$ & $23_{a}(8.6)$ & $65_{a}(7.0)$ & $5_{a}(18.5)$ & $39 a(6.7)$ & \\
\hline $35-45$ & $68_{a}(25.4)$ & $221_{a}(23.8)$ & $7_{a}(25.9)$ & $132_{a}(22.8)$ & \\
\hline $45-55$ & $88_{a}(32.8)$ & $266_{a}(28.6)$ & $8 a(29.6)$ & $150_{a}(25.9)$ & \\
\hline$>55$ & $89_{a}(33.2)$ & $377_{a, b}(40.6)$ & $7 \mathrm{a}, \mathrm{b}(25.9)$ & $259_{b}(44.7)$ & \\
\hline \multicolumn{5}{|l|}{ Hours slept per day (h) } & $<0.01$ \\
\hline$<6$ & $30_{a, b}(11.1)$ & $96_{b}(10.3)$ & $3_{a, b}(11.1)$ & $95 a(16.3)$ & \\
\hline $6-8$ & $219_{a}(80.8)$ & $767_{a}(82.5)$ & $19 \mathrm{a}(70.4)$ & $457_{a}(78.3)$ & \\
\hline $8-10$ & $22_{a, b}(8.1)$ & $67_{a, b}(7.2)$ & $5_{b}(18.5)$ & $32_{a}(5.5)$ & \\
\hline Marital status, Married & $58_{a}(21.4)$ & $136_{b}(14.7)$ & $7 \mathrm{a}, \mathrm{b}(25.9)$ & $101_{a, b}(17.3)$ & 0.03 \\
\hline Have children & $65_{a}(24.0)$ & $289_{a, b}(31.0)$ & $11_{\mathrm{a}, \mathrm{b}}(40.7)$ & $223_{b}(38.3)$ & $<0.01$ \\
\hline $\begin{array}{l}\text { Have worked part-time } \\
\text { once }\end{array}$ & $92_{a}(34.5)$ & $342_{a}(36.8)$ & $15_{a}(55.6)$ & $238_{a}(41.0)$ & 0.05 \\
\hline \multicolumn{5}{|c|}{ View on current medical environment } & $<0.01$ \\
\hline Poor & $116_{a}(43.0)$ & $493_{b}(53.1)$ & $8 \mathrm{a}, \mathrm{b}(29.6)$ & $426_{c}(73.3)$ & \\
\hline Neutral & $145_{a}(53.7)$ & $414_{a}(44.6)$ & $17_{a}(63.0)$ & $135_{b}(23.2)$ & \\
\hline Good & $9 \mathrm{a}(3.3)$ & $21_{a}(2.3)$ & $22_{a}(7.4)$ & $20_{a}(3.4)$ & \\
\hline \multicolumn{5}{|l|}{ Career choice regret } & $<0.01$ \\
\hline With & $75_{a}(27.7)$ & $408_{b}(43.8)$ & $9_{a, b}(33.3)$ & $353_{c}(60.7)$ & \\
\hline Neutral & $43_{a}(15.9)$ & $191_{a}(20.5)$ & $4_{a}(14.8)$ & $91_{a}(15.6)$ & \\
\hline Without & $153_{\mathrm{a}}(56.5)$ & $332_{b}(35.7)$ & $14_{a, b}(51.9)$ & $138_{c}(23.7)$ & \\
\hline
\end{tabular}


Table 1 Characteristics associated with medical students' burnout and (or) depressive symptoms (Continued)

\begin{tabular}{|c|c|c|c|c|c|}
\hline \multirow[t]{2}{*}{ Characteristics } & \multicolumn{4}{|c|}{ Burnout and Depressive Symptoms } & \multirow{2}{*}{$\begin{array}{l}P \\
\text { Value }\end{array}$} \\
\hline & $\begin{array}{l}B(-) \text { and } D(-)[271 \text {, } \\
14.9 \%]\end{array}$ & $\begin{array}{l}B(+) \text { and } D(-)[932, \\
51.4 \%]\end{array}$ & $\begin{array}{l}\text { B (-) and D (+) }[27, \\
1.5 \%]\end{array}$ & $\begin{array}{l}B(+) \text { and D (+)[584, } \\
32.2 \%]\end{array}$ & \\
\hline $\begin{array}{l}\text { Considered dropping out } \\
\text { once }\end{array}$ & $26_{a}(9.6)$ & $100_{a}(10.8)$ & $7_{a, b}(25.9)$ & $186_{b}(32.2)$ & $<0.01$ \\
\hline
\end{tabular}

B (+) Burnout positive; B (-) Burnout negative; D (+) Depressive symptoms positive; D (-) Depressive symptoms negative

Subscript letters $a, b$, $c$ : If the mark letters were the same between any two groups, the difference between the two groups was not statistically significant. If the two groups of markers had different letters, the difference between the two groups was statistically significant

burnout may reflect a "classic" depression process [35]. In brief, these studies point to possible overlap and differences between burnout and depression. In this study, burnout and depressive symptoms were not identical among medical students. The overlap of burnout and depressive symptoms was significant, but the rate was moderate in medical students.

Our findings indicate that almost all the students with depressive symptoms also had burnout, and that the ratio of symptoms in each of the four groups differed widely. Consistent with previous studies, the whole proportion of burnout was higher than that of depressive symptoms [12, 13]. Although previous studies have shown high levels of burnout and depressive symptoms among medical students [36], as well as a strong interplay between burnout and depression [37], they fail to mention that the majority of students with depressive symptoms also suffer from burnout. In fact, in one study, $83.1 \%$ of patients with depression experienced a high level of burnout, and whether they had experienced burnout differed significantly among those individuals [5]. While similar conclusions have been confirmed in studies of overlapping burnout and depressive symptoms in other occupations [38], and other studies have mentioned these overlapping symptoms among medical students [39], the symptom proportions in this relationship were confirmed in the present study. Our results illustrated not only the degree of overlap between burnout and depressive symptoms, but also the tendency to categorize students with depressive symptoms as also burnout students. According to one study, burnout symptoms are more common than depressive symptoms, and the overlap phenomenon is only moderate [40]. On the whole, our study seems to demonstrate this situation, and to hint that depressive symptoms in neurology graduate students may be more related to burnout, which indicates that it is important to assess graduate students for burnout.

In our study, students without burnout or depressive symptoms were used as a reference. The results of multinomial logistic regression showed that the students with only burnout and students with overlapping burnout and depressive symptoms had the same four associated factors. The four factors are similar to those reported in research results for medical interns, but are not exactly the same [41]. Among the comparable factors, being married is protective, consistent with the results of this study; however, having children is a risk factor, in contrast to our findings [41]. Possible reasons for this are the inconsistencies between factors across the two studies and the differences in their populations. Another important reason may be strong social pressure among Chinese young people, which has meant increasingly more of them choosing to marry later and having fewer children [42]. Many families, moreover, cannot afford to have children, and, clearly, graduate students who have no source of income cannot afford to this either. One study found a negative correlation between being married and burnout, possibly because of differences in study subjects [43]. In this study, being married was a protective factor. It may be that marriage plays a greater role in providing emotional support to young couples.

In this study, we observed more related factors that influenced the overlap of students' burnout and depressive symptoms. Some studies assert that burnout is a state of depression, given the genesis of the burnout construct and the overlap of burnout and depression [44]. While this overlap was obvious among neurology graduate students in the present study, there was a significant overlap in the predictors for only burnout and for burnoutdepressive symptoms overlapped. Importantly, the proportions of symptoms in each of the two groups was high, and there was a large differentiation. That is, many students who are burned out do not evidence the diagnostic standard for depressive symptoms. Among students with only depressive symptoms, there was only one significant influencing factor which was probably caused by the sample size of this group being too small to obtain more accurate results. The significant influence of academic year on students' burnout and/or depressive symptoms was reflected in different academic year, which may have been caused by its instability. One survey of burnout among medical undergraduates showed that sophomores and juniors tend to be in the higher level than freshmen $[45,46]$, while another survey on medical graduate students' burnout demonstrates significant differences among different years, with the third year being in the highest level [45, 47]. Most medical postgraduates in China are required to publish articles, 
Table 2 Multinomial analysis of medical students' burnout and (or) depressive symptoms

\begin{tabular}{|c|c|c|c|}
\hline $\begin{array}{l}\text { B (-) and D (-) } \\
\text { [Reference] }\end{array}$ & Variables & OR $(95 \% \mathrm{Cl})$ & $P$ value \\
\hline \multirow[t]{13}{*}{ B (+) and D (-) } & Marital status, Married & $0.44(0.29-0.69)$ & $<0.01$ \\
\hline & Have children & $1.79(1.17-1.74)$ & $<0.01$ \\
\hline & Career choice regret & & \\
\hline & With & $2.26(1.56-3.28)$ & $<0.01$ \\
\hline & Neutral & $2.98(1.84-4.80)$ & $<0.01$ \\
\hline & Without & 1 (Reference) & \\
\hline & Academic year & & \\
\hline & Second-year, master's degree & $1.23(0.80-1.90)$ & 0.34 \\
\hline & Third-year, master's degree & $0.98(0.65-1.46)$ & 0.90 \\
\hline & First-year, doctor's degree & $3.89(1.10-13.75)$ & 0.03 \\
\hline & Second-year, doctor's degree & $1.47(0.54-4.01)$ & 0.45 \\
\hline & Third-year, doctor's degree & $2.39(0.76-7.48)$ & 0.14 \\
\hline & First-year, master's degree & 1 (Reference) & \\
\hline \multirow[t]{7}{*}{$B(-)$ and $D(+)^{b}$} & Academic year & & \\
\hline & Second-year, master's degree & $9.01(1.03-78.62)$ & 0.47 \\
\hline & Third-year, master's degree & $5.44(0.64-46.32)$ & 0.12 \\
\hline & First-year, doctor's degree & $56.23(3.39-933.60)$ & $<0.01$ \\
\hline & Second-year, doctor's degree & $12.47(0.57-271.17)$ & 0.11 \\
\hline & Third-year, doctor's degree & - & - \\
\hline & First-year, master's degree & 1 (Reference) & \\
\hline \multirow[t]{23}{*}{$B(+)$ and $D(+)^{c}$} & Family income (yuan per month & & \\
\hline & $<5000$ & $2.33(1.05-5.18)$ & 0.04 \\
\hline & $5000-10,000$ & $2.15(0.96-4.85)$ & 0.06 \\
\hline & $10,000-15,000$ & $1.63(0.62-4.27)$ & 0.32 \\
\hline & $>15,000$ & 1 (Reference) & \\
\hline & Scores of postgraduate entrance & & \\
\hline & $<300$ & $0.87(0.45-1.69)$ & 0.67 \\
\hline & $300-330$ & $1.87(1.05-3.34)$ & 0.03 \\
\hline & $330-360$ & $1.39(0.76-2.56)$ & 0.28 \\
\hline & $>360$ & 1 (Reference) & \\
\hline & Marital status, Married & $0.55(0.34-0.89)$ & 0.02 \\
\hline & Have children & $1.97(1.24-3.14)$ & $<0.01$ \\
\hline & Career choice regret & & \\
\hline & With & $3.87(2.56-5.86)$ & $<0.01$ \\
\hline & Neutral & $3.56(2.06-6.16)$ & $<0.01$ \\
\hline & Without & 1 (Reference) & \\
\hline & Considered dropping out once & $2.62(1.55-4.43)$ & $<0.01$ \\
\hline & Academic year & & \\
\hline & Second-year, master's degree & $2.33(1.43-3.81)$ & $<0.01$ \\
\hline & Third-year, master's degree & $1.32(0.82-2.12)$ & 0.25 \\
\hline & First-year, doctor's degree & $3.21(0.79-13.00)$ & 0.10 \\
\hline & Second-year, doctor's degree & $2.50(0.84-7.43)$ & 0.10 \\
\hline & Third-year, doctor's degree & $3.69(1.08-12.61)$ & 0.04 \\
\hline
\end{tabular}


Table 2 Multinomial analysis of medical students' burnout and (or) depressive symptoms (Continued)

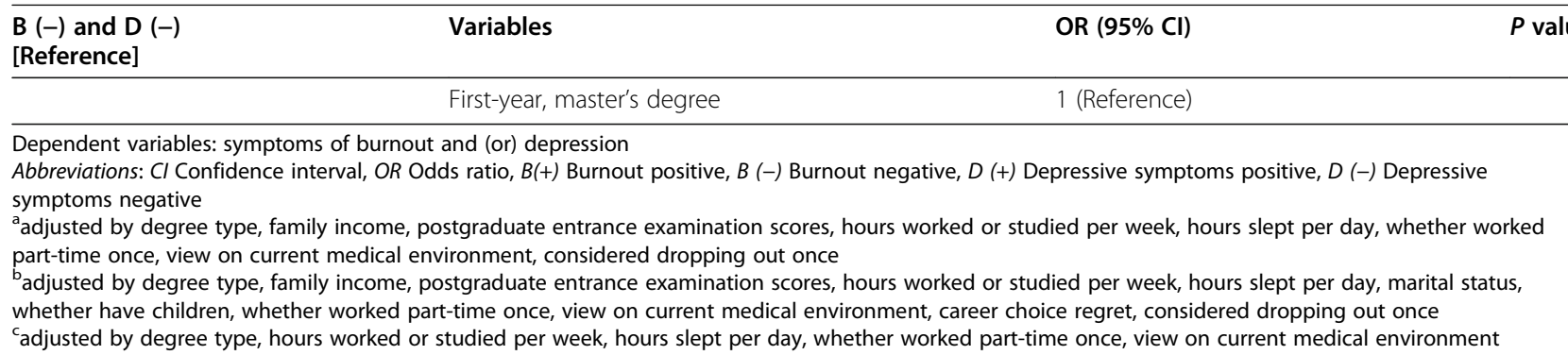

and the increased pressure to complete their studies is likely to impose more stress for senior students.

Burnout and depressive symptoms have long been associated with medical students' lived experience. College students in China live in an exam-oriented education system, which makes learning itself a huge source of pressure [48]. Therefore, relief from burnout and depressive symptoms should be integrated into the daily management of medical graduate students. This study illustrated that a high proportion of the neurology graduate student survey sample evidenced an overlap of burnout and depressive symptoms. Moreover, these students with lower mental health level were more likely to be affected by daily life and/or study. Thus, it is urgent to focus on this group. Further study on overlapping symptoms may provide a new focus for educational administration in their management of students. Studies have shown that higher levels of burnout are associated with reduced help-seeking behavior among people with mental health problems, who may not only suffer from burnout and depressive symptoms, but may also be reluctant to seek treatment owing to psychological pressures such as a sense of shame and fear of disclosure [8, 49]. Additionally, many people may underestimate the severity of the symptoms and may not seek help when they think they are "burned out" [50]. The present study found a tendency for depressive symptoms to be included in the burnout subgroup, and also found that the influencing factors were similar. It is suggested that improvement measures in burnout or depressive symptoms can affect all of these students, thus alleviating their burnout and depressive symptoms may eventually become more efficient. For this reason, it is important to focus on the overlap between burnout and depressive symptoms.

Education departments should pay more attention to adjustments in medical students' curriculum and leisure activities, so students can combine work with rest. University administrators should improve the prevention of students' negative psychological issues, help students manage them, and pay attention to vulnerable groups. Furthermore, increased action should be taken and more time spent communicating with students who evidence overlapping burnout and depressive symptoms instead of waiting for them to ask for help. It is recommended that students' depressive symptoms and burnout be assessed concurrently, and that students with serious results be given appropriate medications and/or psychological intervention. Finally, it is essential that sensitive words such as "stigma" are avoided, to reduce the potential for causing students harm.

\section{Limitations}

First, this study was a cross-sectional design and was limited to graduate students in neurology, thus restricting the external validity of the study that we were unable to assess any causal relationship. The results should be validated using longitudinal methods in future studies. Second, only self-reported questionnaires were used for evaluation. Third, this study was not administered using a random sampling methods may cause an indeterminate response rate. Fourth, the information collected by the self-report questionnaire had certain limitations, such as marital tension, physical activity, social support and personality traits, which were not reflected in this study. Finally, although prime-MD is widely used to assess depressive symptoms, it may not be sufficient to measure the intensity of depressive symptoms. In subsequent studies, more comprehensive measurement methods may be needed to further support the results of this study.

\section{Conclusions}

This study identified an obvious overlap ratio of burnout and depressive symptoms among Chinese neurology graduate students. Some similarities and differences in related influencing factors were found, which indicates that the occurrence of depressive symptoms among medical students is closely related to whether they are burned out. Further, burnout may be a pre-depression state. While burnout often occurs alone, depressive symptoms do not typically occur alone, which provides more insights into and evidence about the mental health of medical students. 


\section{Supplementary Information}

The online version contains supplementary material available at https://doi. org/10.1186/s12909-021-02511-3.

\section{Additional file 1.}

\section{Acknowledgements}

Not applicable.

\section{Authors' contributions}

Wei Zhou, Juncai Pu and Xiaogang Zhong conceived and designed the study, Wei Zhou wrote and revised the original draft. Juncai Pu and Xiaogang Zhong reviewed and edited the original draft, and finally jointly approved the draft. Yiyun Liu, and Haiyang Wang collected and entered the data. Wensong Yang and Teng Teng were involved in the data entry and data proofread. Li Fan, and Lu Tian analyzed the data, and prepared tables. Peng Xie revised the final version of the manuscript, approved the final draft, and acquired the financial support for the project leading to this publication. All authors read and approved the final manuscript.

\section{Funding}

The author(s) disclosed receipt of the following financial support for the research, authorship and/or publication of this article: This work was supported by the National Key Research and Development Program of China (Grant No. 2017YFA0505700), the Non-profit Central Research Institute Fund of Chinese Academy of Medical Sciences (Grant No. 2019PT320002), and the Natural Science Foundation Project of China (Grant No. 81820108015).

\section{Availability of data and materials}

The datasets generated during and analyzed during the current study are not publicly available due to the data confidentiality requirements of Chinese Medical Doctor Association but are available from the corresponding author on reasonable request.

\section{Ethics approval and consent to participate}

Ethics approval was granted by the ethics committee of Chongqing Medical University. Informed consent was obtained from all participant. All study procedures, protocols and methods involving human participants were in accordance with the ethical standards of the 1964 Helsinki declaration.

\section{Consent for publication}

Not applicable.

\section{Competing interests}

The author(s) declared no potential conflicts of interest with respect to the research, authorship, and/or publication of this article.

\section{Author details}

'School of Public Health and Management, Chongqing Medical University, Chongqing 400016, China. ${ }^{2} \mathrm{NHC}$ Key Laboratory of Diagnosis and Treatment on Brain Functional Diseases, The First Affiliated Hospital of Chongqing Medical University, Yuzhong District, Chongqing, China. ${ }^{3}$ Department of Neurology, The First Affiliated Hospital of Chongqing Medical University, Chongqing 400016, China. ${ }^{4}$ Key Laboratory of Psychoseomadsy, Stomatological Hospital of Chongqing Medical University, Chongqing 401147, China. ${ }^{5}$ Stomatological Hospital of Chongqing Medical University, Chongqing 401147, China. ${ }^{6}$ China Neurologist Association of Chinese Medical Doctor Association, Beijing 100010, China.

\section{Received: 22 September 2020 Accepted: 21 January 2021}

\section{Published online: 02 February 2021}

\section{References}

1. Maslach C, Jackson SE, Leiter MP. Maslach burnout inventory manual. 3rd ed. Palo Alto (CA): Consulting Psychologists Press; 1996. p. 191-218.

2. Maslach C, Schaufeli WB, Leiter MP. Job burnout. Annu Rev Psychol. 2001;52: 397-422.

3. Ahola K, Honkonen T, Kivimäki M, et al. Contribution of burnout to the association between job strain and depression: the health 2000 study. J Occup Environ Med. 2006;48:1023-30.
4. Njim T, Mbanga CM, Tindong M, et al. Burnout as a correlate of depression among medical students in Cameroon: a cross-sectional study. BMJ Open. 2019 May 5;9(5):e027709.

5. Chiu LY, Stewart K, Woo C, Yatham LN, Lam RW. The relationship between burnout and depressive symptoms in patients with depressive disorders. J Affect Disord. 2015;172:361-6.

6. Melchior M, Caspi A, Milne BJ, Danese A, Poulton R, Moffitt TE. Work stress precipitates depression and anxiety in young, working women and men. Psychol Med. 2007;37(8):1119-29.

7. Verkuilen J, Bianchi R, Schonfeld IS, et al. Burnout-Depression Overlap: Exploratory Structural Equation Modeling Bifactor Analysis and Network Analysis. Assessment. 2020:1073191120911095 [published online ahead of print, 2020 Mar 10]. https://doi.org/10.1177/1073191120911095.

8. Fitzpatrick O, Biesma R, Conroy RM, et al. Prevalence and relationship between burnout and depression in our future doctors: a cross-sectional study in a cohort of preclinical and clinical medical students in Ireland. BMJ Open. 2019;9(4):e023297.

9. Dyrbye LN, Thomas MR, Massie FS, et al. Burnout and suicidal ideation among U.S. medical students. Ann Intern Med. 2008;149(5):334-41.

10. Youssef FF. Medical student stress, burnout and depression in Trinidad and Tobago. Acad Psychiatry. 2016:40(1):69-75.

11. Talih F, Daher M, Daou D, et al. Examining burnout, depression, and attitudes regarding drug use among Lebanese medical students during the 4 years of medical school. Acad Psychiatry. 2018;42(2):288-96.

12. Rotenstein LS, Ramos MA, Torre M, Segal JB, Peluso MJ, Guille C, Sen S, Mata DA. Prevalence of depression, depressive symptoms, and suicidal ideation among medical students: a systematic review and meta-analysis. JAMA. 2016;316(21):2214-36.

13. Frajerman A, Morvan $Y$, Krebs MO, et al. Burnout in medical students before residency: a systematic review and meta-analysis. Eur Psychiatry. 2019;55:3642.

14. Bert F, Lo Moro G, Corradi A, et al. Prevalence of depressive symptoms among Italian medical students: the multicentre cross-sectional "PRIMES" study. PLoS One. 2020;15(4):e0231845.

15. Pagnin D, De Queiroz V, De Oliveira Filho MA, et al. Burnout and career choice motivation in medical students. Medical Teacher. 2013;35(5):388-94.

16. Dyrbye LN, Massie FS Jr, Eacker A, et al. Relationship between burnout and professional conduct and attitudes among US medical students. JAMA. 2010;304(11):1173-80.

17. Grace MK. Depressive symptoms, burnout, and declining medical career interest among undergraduate pre-medical students. Int J Med Educ. 2018; 9:302-8.

18. Schwenk TL, Davis L, Wimsatt LA. Depression, stigma, and suicidal ideation in medical students. JAMA. 2010;304(11):1181-90.

19. Lu T, Juncai $P$, Yiyun $L$, et al. Relationship between burnout and career choice regret among Chinese neurology postgraduates. BMC Med Educ. 2019:19(1):162.

20. Zhong X, Liu Y, Pu J, et al. Depressive symptoms and quality of life among Chinese medical postgraduates: a national cross-sectional study. Psychol Health Med. 2019;24(8):1015-27.

21. Bianchi R, Schonfeld IS, Laurent E. Burnout-depression overlap: a review. Clin Psychol Rev. 2015;36:28-41.

22. Wurm W, Vogel $\mathrm{K}$, Holl $\mathrm{A}$, et al. Depression-burnout overlap in physicians. PLoS One. 2016;11(3):e0149913.

23. Bianchi R, Schonfeld IS. Burnout-depression overlap: Nomological network examination and factor-analytic approach. Scand J Psychol. 2018;59(5):532-9.

24. Bianchi R, Brisson R. Burnout and depression: causal attributions and construct overlap. J Health Psychol. 2019;24(11):1574-80.

25. Ahola $\mathrm{K}$, Honkonen $\mathrm{T}$, Virtanen $\mathrm{M}$, et al. Interventions in relation to occupational burnout: the population-based health 2000 study. J Occup Environ Med. 2007:49(9):943-52.

26. Karp JF, Levine AS. Mental health Services for Medical Students - time to act. N Engl J Med. 2018;379(13):1196-8.

27. Zhou X, Pu J, Zhong X, et al. Burnout, psychological morbidity, job stress, and job satisfaction in Chinese neurologists. Neurology. 2017;88(18):1727-35.

28. Bianchi R, Laurent E. Emotional information processing in depression and burnout: an eye-tracking study. Eur Arch Psychiatry Clin Neurosci. 2015; 265(1):27-34.

29. Spitzer RL, Williams JB, Kroenke K, et al. Utility of a new procedure for diagnosing mental disorders in primary care. The PRIME-MD 1000 study. JAMA. 1994;272(22):1749-56 
30. Jackson ER, Shanafelt TD, Hasan O, Satele DV, Dyrbye LN. Burnout and alcohol buse/dependence among US medical students. Acad Med. 2016; 91(9):1251-6.

31. Dyrbye LN, West CP, Satele D, et al. Burnout among US medical students, residents, and early career physicians relative to the general US population. Acad Med. 2014;89(3):443-51.

32. Glass DC, Mcknight JD. Perceived control, depressive symptomatology, and professional burnout: a review of the evidence. Psychol Health. 1996;11(1): 23-48.

33. Tateno M, Jovanović N, Beezhold J, et al. Suicidal ideation and burnout among psychiatric trainees in Japan. Early Interv Psychiatry. 2018;12(5):9357.

34. Bianchi R, Schonfeld IS, Laurent E. Biological research on burnoutdepression overlap: long-standing limitations and on-going reflections. Neuroence Biobehav Rev. 2017:83:238-9.

35. Schonfeld IS, Bianchi R, Palazzi S. What is the difference between depression and burnout? An ongoing debate. Rivista Psichiatria. 2018;53(4):218-9.

36. Dyrbye LN, West CP, Satele D, et al. Burnout among U.S. medical students, residents, and early career physicians relative to the general U.S. population. Acad Med. 2014;89(3):443-51.

37. Ahola K, Honkonen T, Isometsä E, et al. The relationship between jobrelated burnout and depressive disorders--results from the Finnish health 2000 study. J Affect Disord. 2005;88(1):55-62.

38. Schonfeld IS, Bianchi R. Burnout and depression: two entities or one? J Clin Psychol. 2016;72(1):22-37.

39. Al-Alawi M, Al-Sinawi $\mathrm{H}$, Al-Qubtan $\mathrm{A}$, et al. Prevalence and determinants of burnout syndrome and depression among medical students at Sultan Qaboos University: a cross-sectional analytical study from Oman. Arch Environ Occup Health. 2019;74(3):130-9.

40. Colville GA, Smith JG. The overlap between burnout and depression in ICU staff. Crit Care Med. 2017:45(10):e1102-3.

41. Rotenstein LS, Zhao Z, Mata DA, et al. Substantial Overlap Between Factors Predicting Symptoms of Depression and Burnout Among Medical Interns. J Gen Intern Med. 2020 [published online ahead of print, 2020 Feb 5]. https:// doi.org/10.1007/s11606-020-05664-x.

42. Lin M. The pressure and anxiety of contemporary Chinese young people. Peoples Tribune. 2019:33:78-80 Article in Chinese.

43. Xie Z, Wang A, Chen B. Nurse burnout and its association with occupational stress in a cross-sectional study in Shanghai. J Adv Nurs. 2011;67(7):1537-46.

44. Bianchi R, Schonfeld IS, Laurent E. Is it time to consider the "burnout syndrome" a distinct illness? Front Public Health. 2015;3:158.

45. Chunming WM, Harrison R, Maclntyre R, Travaglia J, Balasooriya C. Burnout in medical students: a systematic review of experiences in Chinese medical schools. BMC Med Educ. 2017:17(1):217.

46. Wang FF, Jiang HY. Investigation and analysis of current situation of medical students' learning burnout. Jian Nan Wenxue. 2011:8:281 Article in Chinese.

47. Zheng XM, Li WY. An analysis on relevant factors of medical postgraduates' learning burnout. J Xinjiang Med University. 2015;38(06):781-3 Article in Chinese.

48. Cheng J, Zhao YY, Wang J, Sun YH. Academic burnout and depression of Chinese medical students in the pre-clinical years: the buffering hypothesis of resilience and social support. Psychol Health Med. 2020;25(9):1094-105. https://doi.org/10.1080/13548506.2019.1709651.

49. Adhikari A, Dutta A, Sapkota S, et al. Prevalence of poor mental health among medical students in Nepal: a cross-sectional study. BMC Med Educ. 2017;17(1):232 Published 2017 Nov 28.

50. Bianchi R. Do burnout and depressive symptoms form a single syndrome? Confirmatory factor analysis and exploratory structural equation modeling bifactor analysis [published online ahead of print, 2020 Feb 4]. J Psychosom Res. 2020;131:109954.

\section{Publisher's Note}

Springer Nature remains neutral with regard to jurisdictional claims in published maps and institutional affiliations.

Ready to submit your research? Choose BMC and benefit from:

- fast, convenient online submission

- thorough peer review by experienced researchers in your field

- rapid publication on acceptance

- support for research data, including large and complex data types

- gold Open Access which fosters wider collaboration and increased citations

- maximum visibility for your research: over $100 \mathrm{M}$ website views per year

At $\mathrm{BMC}$, research is always in progress.

Learn more biomedcentral.com/submissions 